\title{
Multipl Sklerozda Oral Tedavi Seçenekleri
}

\section{Oral Treatment Options for Multiple Sclerosis}

\author{
Murat ALPUA ${ }^{1}$
}

${ }^{1}$ Çankırı Devlet Hastanesi, ÇANKIRI

\begin{abstract}
ÖZET
Relapsing Remitting Multipl Skleroz (RRMS) için tedavi seçenekleri gün geçtikçe artmaktadır. Bazı oral tedavi seçeneklerinin de tedavide fayda sağlayabileceği yakın zamanda yapılan çeşitli araştırmalarla gösterilmiştir. Ancak bu tedavi seçeneklerinin klinik faydalılı̆̆ı ve güvenilirliği hakkında halen bazı şüpheler devam etmektedir. Bu derlemede oral ajanların etki mekanizmaları, etkinlikleri ve güvenilirlikleri hakkında şimdiye kadar yürütülmüş çalışmaların özetlenmesi amaçlanmıştır.
\end{abstract}

Anahtar Kelimeler: Relapsing remitting multipl skleroz, oral tedavi

\section{GíRiș}

Multipl skleroz (MS), fiziksel özürlülüğe neden olan, genç nüfusu etkileyen, ataklar ve remisyonlarla seyreden bir hastalıktır.Genç erişkin popülasyonda özürlülüğe sebep olan en s1k nörolojik hastalıklardan biri olması sebebiyle tedavi için yapılan araştırmalar büyük ilgi çekmektedir. Neyseki MS için tedavi seçenekleri gün geçtikçe artmakta ve gelecek için umut vermektedir. Hâlihazırda özellikle RRMS için birçok tedavi seçeneği bulunmaktadır. Beta-interferonlar, glatiramer asetat, mitoksantron, natalizumab, alemtuzumab, daklizumab, rituksimab şu haliyle MS tedavi seçeneği olan parenteral tedavi seçenekleridir. Son yillarda bu parenteral tedavi seçeneklerine alternatif olarak sunulan oral ajanlarla ilgili birçok çalışmalar yürütüle gelmektedir. $\mathrm{Bu}$ oral ajanlar fingolimod, kladribin, teriflunomid, laquinimod ve dimetil fumarattır.

\section{ABSTRACT}

Options for the treatment of relapsing remitting multiple sclerosis (RRMS) is increasing rapidly. Several oral treatments have shown benefit in several studies. However, the clinical effectiveness and safety of these treatment options are stil in some doubts. In this review, investigations those had been studied about the mechanism of action, efficacy and safety of these oral agents have been summarized.

Keywords: Relapsing remitting multiple sclerosis, oral treatment

\section{Fingolimod}

Fingolimod (FTY720) 2010 y1lında Kuzey Amerika'da MS tedavisi için onaylanmış bir oral sfingosin-1-fosfat (S1P) reseptör modülatörüdür. Bu ilaç ikinci basamak tedavi seçeneği olarak kullanılmaktadır. Fingolimod sfingosin-1-fosfat(S1P) reseptörlerini modüle eder ve güçlü bağışıklık düzenleyici özelliklere sahiptir (1-3). S1P reseptörleri lenfoid ve nöral dokularda eksprese edilir. Fingolimod lipofilik olduğu için santral sinir sistemine kolayca girer ve bazı S1P reseptör alt tiplerine bağlanarak mekanizması tam olarak açıklanamayan nöroprotektif ve onarıcı etkilerini oluşturur.

Fingolimodun MS tedavisindeki etkinliği majör klinik çalışmalarda gösterilmiştir. TRANSFORMS çalışması en azından bir relaps öyküsü olan 1292 RRMS 
hastasının oral fingolimod ( 0,5 ya da $1.25 \mathrm{mg} /$ gün) ya da IFN- $\beta 1$ a ( $30 \mu \mathrm{g}$ haftada bir)'ya randomize edildiği 12 aylık çift kör klinik çalışmadır (4). 1153 hasta çalışmayı tamamlamıştır. Yıllık relaps oranı hem 0,5 $\mathrm{mg}(0.16)$ hem de $1.25 \mathrm{mg}$ (0.20) fingolimod grubunda IFN- $\beta$ 1a (0.33) grubuna göre anlamlı oranda düşük saptand1. 6 ay süren randomize Faz 2 çalışmada 281 aktif relapslı MS hastası plasebo ve $1.25 \mathrm{mg} /$ gün ile $5 \mathrm{mg} /$ gün şeklinde iki ayrı kolda oral fingolimod tedavilerine randomize edildiler (5). Gadolinuim tutan MR lezyonları plasebo grubuna karşı fingolimod gruplarında anlamlı olarak azalmıştı(1,25 mg,p<0,001; 5,0 mg, $\mathrm{p}=0,006)$. Y1ll1k relaps oranındaki relatif azalma yüzdesi yüksek ve düşük doz fingolimod grubunda $\% 53$ ve $\% 55$ oranındayd. FREEDOMS çalışmasına 1272 RRMS hastası katıldı ve 1033 hasta çalışmayı tamamladı (6). Plasebo ile karşılaştırıldığında $1.25 \mathrm{mg}$ grubunda \%60 (p<0,001) ve $0,5 \mathrm{mg}$ fingolimod grubunda $\% 54(\mathrm{p}<0.001)$ y1llık relaps oranında düşme saptandı. 24 ay sonunda fingolimodun ilk relaps zamanını anlamlı derecede ertelediği ve plasebo grubuna kıyasla daha geniş bir hasta grubunun relaps yaşamadığı sonucuna varılmıştır.

Fingolimod kullanımı ile ilişkili nadir ancak önemli bir sorun ise herpes zoster enfeksiyonu gelişme riski ve bunun nörolojik komplikasyonlarıdır. Bu nedenle, VZV'ye karşı bağışık olmayan hastaların fingolimod tedavisi öncesi aşılanmış olmaları gerekmektedir. Fingolimod klinik kullanımı ile ilgili diğer pratik husus ise fingolimodun ilk dozundan sonra gelişebilen bradikardi, bradiaritmiler ve zorlu ekspiratuar hacimde hafif bir azalma olmasıdır. Bu sebeple Fingolimod ilk doz tatbiki sonrası 6 saatlik bir gözlem tavsiye edilmektedir.

\section{Kladribin}

Sentetik pürin nükleozid analoğu olan kladribin (2kloro-2-deoksiadenozin) pürin nükleozid transporterları ile hücreye girer ve deoksitidin kinaz ile fosforile edilir $(7,8)$. Kladribin bu şekilde lenfositlerde DNA sentezi ve onarımını engelleyerek uzun süren lenfopeniye yol açar. RRMS'te oral hastalık modifiye edici ajanlar için tamamlanmış ilk faz 3 çalışma CLARITY çalışmasıdır ve 1326 hasta üzerinde yapılmıştır (7). Bu çalışmada Kladribin plaseboya kıyasla anlamlı şekilde düşük yıllık relaps oranlarına sahipti $(3,5 \mathrm{mg} / \mathrm{kg}$ grubunda $0,14,5.25 \mathrm{mg} / \mathrm{kg}$ grubunda 0,15 ve plasebo grubunda 0,33; p<0,001; düşük doz ya da yüksek doz grubunda plaseboya kıyasla). Ayrıca kladribin hem daha düşük EDSS progresyon oranına hem de aktif MR lezyonlarının sayısında azalmayla da ilişkili bulundu $(\mathrm{p}<0.001)$.

Kladribinle ilişkili yan etkiler ise lenfositopeni (\%21,6 düşük doz grubunda ve \%31,5 yüksek doz grubunda buna karşılık \%1,8 plasebo grubunda) ve herpes zosterdir $(3,5 \mathrm{mg}$ grubunda 8 hasta ve $5.25 \mathrm{mg}$ grubunda 12 hasta buna karşıllk plasebo grubunda yoktu). Ciddi enfeksiyonlar plasebo grubunda \%1,6, $3.5 \mathrm{mg} / \mathrm{kg}$ grubunda $\% 3,5.25 \mathrm{mg} / \mathrm{kg}$ grubunda $\% 2,9$ 'du. Kladribinin $3,5 \mathrm{mg} / \mathrm{kg}$ grubunda 6 hastada $(\% 1,4)$ ve $5.25 \mathrm{mg} / \mathrm{kg}$ grubunda 4 hastada $(<\% 1)$ neoplazm gelişirken plasebo grubunda neoplazm gözlenmedi.

CLARITY çalışması ilk basamak parenteral hastalık modifiye edici ajanlara iyi yanıt vermeyen yüksek aktiviteli RRMS'li hastalarda kladribinin efektif olduğunu göstermiştir (9). Halen RRMS hastaları üzerinde oral kladribin için 3 koldan devam eden randomize kontrollü çalışmalar bulunmaktadır (ONWARD, ORACLE-MS ve CLARITY extension çalışması).

\section{Teriflunomid}

Teriflunomid romatoid artrit için kullanılan leflunomidin aktif metabolitidir (10). Teriflunomid pirimidin sentezi için elzem olan mitokondrial enzim dihidrooratat dehidrogenaz aktivitesini azaltır. T lenfosit çoğalması büyük oranda pirimidin sentezine bağlıdır. Ancak bu ilaç az miktarda lenfositopeniye sebep olduğundan bu süreç ilaç etkisinin yalnızca bir kısmını kapsamaktadır. 
RRMS'li hastalarda yapılan faz 2 teriflunomid çalışmasında beyin MR'lerindeki inaktif lezyonlarda azalma olduğu gösterilmiştir (11). RRMS'li hastalarda teriflunomidle yapılan bir başka randomize kontrollü çalışmada yıllık relaps oranı ve özürlülük progresyonu değerlendirilmiştir (12-TEMSO çalışması). Klinik çalışma süresince 108 hafta içerisinde 18 ile 55 yaş arası, EDSS skoru 0 ile 5.5 arasında olan ve çalışma başlangıcı öncesi bir yılda en az bir relapsı ya da son 2 yılda en az iki relapsı olan 1088 MS hastası plasebo, $7 \mathrm{mg} /$ gün ya da $14 \mathrm{mg} /$ gün teriflunomide birebir olarak randomize edildi. Yıllık relaps oranlarında, plaseboya kıyasla $7 \mathrm{mg}$ /gün teriflunomid grubunda $\% 31.2$ ve $14 \mathrm{mg} /$ gün teriflunomid grubunda $\% 31.5$ gibi ciddi azalma tespit edildi $(\mathrm{p}<0.001)$. Ayrica her iki dozla teriflunomidle tedaviyle MR sonuçlarında pozitif etkiler elde edildi.

Teriflunomidle tedavi edilen hastalarda ciddi yan etkiler olarak diyare, bulantı, saç tellerinde incelme ve hafif derecede karaciğer enzimlerinde yükselme görüldü.

\section{Laquinimod}

Laquinimod linomid (roquinimex)'in türevidir. Linomid deneysel otoimmün ensefalitin progresyonunu efektif olarak engellemiş ve ön klinik bilgiler MS'deki etkinliğini göstermiştir (13). Ancak bir faz 3 klinik çalışma öngörülemeyen güvenlik endişeleri sebebiyle durdurulmak zorunda kalmıştır $(13,14)$. Laquinimod linomidden daha iyi tolere edilebilir gözükmektedir. Bu ajan fazla immünsüpresyona sebep olmadan Th2 ve Th3 sitokinlerine dönüşümü indüklemektedir (15-17).

Laquinimod MS tedavisi için bir faz 3 klinik çalışmada değerlendirilmiştir. 2 yıllık Faz 3 randomize, çift-kör, plasebo-kontrollü klinik çalışmada (ALLEGRO) RRMS'li 1106 hasta plaseboya karşı $0.6 \mathrm{mg} /$ gün laquinimod tedavisine randomize edilmiştir. Laquinimod ile tedavi plaseboya kıyasla özürlülük progresyonunda azalma (\%11'e karş1 \%15.7, hazard oranı 0.64 , güvenlik aralığ $\% 95 ; P=0.01$ ) ve yıllık relaps oranında azalma $\quad(0.30 \pm 0.02 \quad$ karş1 $0.39 \pm 0.03, P=0.002$ ) ile ilişkili bulunmuştur. Laquinimod tedavisi alan hastalarda kontrast tutan, yeni ya da genişleyen T2 ağırlıklı lezyonların ortalama kümülatif sayısı azalmıştır. Buna ek olarak MS hastalarının laquinimod ile tedavileriyle plaseboya kıyasla beyin atrofisindeki progresyondaki \%33'lük bir azalma tespit edilmiştir $(\mathrm{p}<0.0001)$.

\section{Dimetil Fumarat}

BG-12, dimetil fumaratın oral formülasyonudur ve monometil fumarata metabolize edilir. Dimetil fumarat ve onun primer metaboliti olan monometilfumarat merkezi sinir sistemindeki oksidatif stres ilişkili nöronal ölümü ve myelin hasarını önlemektedirler. Astroglial ve mikroglial hücrelerdeki detoksifikasyon enzimlerinin ekspresyonu ve adezyon molekül ekspresyonu ile ilaç indüksiyonlu daha fazla antiinflamatuar sitokin dönüşümü gibi bazı nöroprotektif ve anti-inflamatuar mekanizmalar bu ilaca atfedilmiştir (18-21).

BG-12'nin MS tedavisindeki etkinliği DEFINE çalışmasında belirlenmiştir. $\mathrm{Bu}$ klinik çalışma 2 yıl süreli faz 3 çift kör plasebo kontrollü doz karşılaştırmalı 1234 hastanın iki farklı dozda (peroral 240mg BID ya da TID) BG-12'ye ve plaseboya randomize edildiği bir çalışmadır. Her iki dozda BG-12 yıllık relaps oranını düşürmede, yeni ve genişleyen T2 ağırlıklı hiperintens lezyonların sayısını azaltmada ve özürlülük progresyonunu yavaşlatmakta plaseboya kıyasla daha üstün bulunmuştur (22). DEFINE çalışmasının sonuçlarına dayanarak BG-12'nin plaseboyla karşılaştırılabilir bir güvenlik profili mevcut olduğu gözükmektedir.

New England Journal of Medicine'de yakın zamanda yayınlanan iki çalışma BG-12'nin MS tedavisindeki etkinliğini göstermiştir(23,24). Bu çalışmalarından ilkinde RRMS'li hastalar BG-12, glatiramer asetat ve plaseboya randomize edilmiştir. 24 aylık çalışma sonrasında yıllık relaps oranı günde iki kez 240mg BG- 
12 grubunda (0.22), günde $3 \mathrm{kez} 240 \mathrm{mg}$ BG-12 grubunda(0.20) ve glatiramer asetat grubunda (0.29) plaseboya (0.40)kıyasla düşük saptandı (Relatif azalmalar: 480mg/gün BG-12, \%12.44, p<0.001; $720 \mathrm{mg} /$ gün BG-12, \%51, p<0.001; glatiramer asetat, $\% 29, p=0.01$ ). Plaseboyla karşılaştırıldığında günde iki kez BG-12,günde 3 kez BG-12 ve glatiramer asetat tedavileriyle yeni ve genişleyen T2 ağırlıklı hiperintens lezyonlar ve yeni T1 ağırlıklı hipointens lezyonların sayısında anlamlı düzeyde azalma saptandı ( $\mathrm{p}<0.001)$. Diğer çalışma ise faz 3 randomize çift kör plasebo kontrollü RRMS hastalarının içine alındığı oral BG-12 tedavi çalışmasıdır. Hastalar günlük iki doz BG-12, günlük 3 kez BG-12 ve plaseboya randomize edilmişlerdir. 24 aylık takip sonrası yıllık relaps oranları düşük doz BG-12 grubunda 0.17,yüksek doz grubunda 0.19 ve plasebo grubunda 0.36 olarak

\section{KAYNAKLAR}

1. Aktas O,Kury P, Kieseier B,Hartung HP. Fingolimod is a potential novel therapy for multiple sclerosis. Nat Rev Neurol. 2010; 6(7): 373-82. Doi: 10.1038/nrneurol.2010.76.

2. Cohen JA, Chun J. Mechanisms of fingolimod's efficacy and adverse effects in multiple sclerosis. Ann Neurol. 2011; 69: 759-77.

3. Ingwersen J, Aktas O, Kuery P, Kieseier B, Boyko A, Hartung HP. Fingolimod in multiple sclerosis: mechanisms of action and clinical efficac

y. Clin Immunol. 2012; 142(1): 15-24. Doi: 10.1016/j.clim.2011.10.008.

4. Cohen JA, Barkhof F, Comi G, Hartung HP, Khatri BO, Montalban X, Pelletier J, Capra R, Gallo P, Izquierdo G, Tiel-Wilck K, de Vera A, Jin J, Stites T, Wu S, Aradhye S, Kappos L; TRANSFORMS Study Group. Oral fingolimod or intramuscular interferon for relapsing multiple sclerosis. N Engl J Med. 2010; 362(5): 402-15.

Doi: 10.1056/NEJMoa0907839.

5. Kappos L, Antel J, Comi G, Montalban X, O'Connor P, Polman CH, Haas T, Korn AA, Karlsson G, Radue EW; FTY720 D2201 Study Group. Oral fingolimod (FTY720) for relapsing multiple sclerosis. N Engl J Med. 2006; 355: 112440. saptand. MS hastalarının BG-12 ile tedavisiyle plaseboya kıyasla kontrast tutan lezyonların sayısı ve yeni ve genişleyen T2 ağırlıklı hiperintens beyin MR lezyonlarında azalma saptand $1 \quad(\mathrm{p}<0.001) . B G-12$ tedavisiyle ilişkili yan etkiler ise karın ağrısı, bulantı, diyare, lenfopeni ve karaciğer enzimlerinde artıştır.

\section{Sonuç}

Görüldüğü gibi çeşitli oral ilaçlar RRMS tedavisinde yeni faydalar göstermiştir. Ancak oral ilaçların bulunması bunların tam olarak zararsız ve uygun tedaviler olduğu anlamına gelmemektedir. Son 20 yılda MS tedavisindeki ciddi gelişmeler olmuştur ve halen çalışmalara devam edilmektedir. Halen MS tedavisi için küratif bir tedavi olasılığına uzak olsak da, devam eden çalışmalar, geleceğin, MS hastaları için aydınlık olduğunu göstermektedir.

6. Kappos L, Radue EW, O'Connor P, Polman C, Hohlfeld R, Calabresi P, Selmaj K, Agoropoulou C, Leyk M, Zhang-Auberson L, Burtin P; FREEDOMS Study Group. A placebo-controlled trial of oral fingolimod in relapsing multiple sclerosis. NEngl J Med. 2010; 362: 387-401.

7. Hartung HP, Aktas O, Kieseier B, Comi GC. Development of oral cladribine for the treatment of multiple sclerosis. J Neurol. 2010; 257: 163-70.

8. Liliemark J. The clinical pharmacokinetics of cladribine. Clin Pharmacokinet. 1997; 32: 120-31.

9. Giovannoni G, Cook S, Rammohan K, Rieckmann P, Sørensen PS, Vermersch P, Hamlett A, Viglietta V, Greenberg S; CLARITY study group. Sustained disease-activity-free status in patients with relapsing-remitting multiple sclerosis treated with cladribine tablets in the CLARITY study: a posthoc and subgroup analysis. Lancet Neurol2011; 10 : 329-37.

10. Fontoura P,Garren H. Multiple sclerosis therapies: molecular mechanisms and future. Results Probl Cell Differ. 2010; 51: 259-85. 
11. O'Connor PW, Li D, Freedman MS, Bar-Or A, Rice GP, Confavreux C, Paty DW, Stewart JA, Scheyer R; Teriflunomide Multiple Sclerosis Trial Group; University of British Columbia MS/MRI Research Group. A Phase II study of the safety and efficacy of teriflunomide in multiple sclerosis with relapses. Neurology. 2006; 66: 894-900.

12. O'Connor P, Wolinsky JS, Confavreux C, Comi G, Kappos L, Olsson TP, Benzerdjeb H, Truffinet P, Wang L, Miller A, Freedman MS; TEMSO Trial Group. "Randomized trial of oral teriflunomide for relapsing multiple slerosis,” New Eng J Med. 2011; 365(14): 1293-1303.

13. Noseworthy JH, Wolinsky JS, Lublin FD, Whitaker JN, Linde A, Gjorstrup P, Sullivan HC. Linomide in relapsing and secondary progressive MS: part I: trial design and clinical results.North American Linomide Investigators. Neurology. 2000; 54: 1726-33.

14. Wolinsky JS, Narayana PA, Noseworthy JH, Lublin FD, Whitaker JN, Linde A, Gjörstrup P, Sullivan HC. Linomide in relapsing and secondary progressive MS: part II: MRI results. MRI Analysis Center of the University of Texas-Houston, Health Science Center, and the North American Linomide Investigators. Neurology. 2000; 54: 1734-41.

15. Brunmark $\quad C^{1}$, Runström A, Ohlsson L, Sparre B, Brodin T, Aström M, Hedlund G. The new orally active immunoregulator laquinimod (ABR215062) effectively inhibits development and relapses of experimental autoimmune encephalomyelitis. J Neuroimmunol. 2002; 130: 163-72.

16. Zou LP, Abbas N, Volkmann I, Nennesmo I, Levi M, Wahren B, Winblad B, Hedlund G, Zhu J. Suppression of experimental autoimmune neuritis by ABR-215062 is associated with altered Th1/Th2 balance and inhibited migration of inflammatory cells into the peripheral nevre tissue. Neuropharmacology. 2002; 42: 731-39.

17. Bruck W, Wegner C. Insight into the mechanism of laquinimod action. J Neurol Sci. 2011; 306: 173-79.
18. Kappos L, Gold R, Miller DH, Macmanus DG, Havrdova E, Limmroth V, Polman CH, Schmierer K, Yousry TA, Yang M, Eraksoy M, Meluzinova E, Rektor I, Dawson KT, Sandrock AW, O'Neill GN; BG-12 Phase IIb Study Investigators. Efficacy and safety of oral fumarate in patients with relapsingremitting multiple sclerosis: a multicentre, randomised, double-blind, placebo-controlled phase IIb study. Lancet. 2008; 372: 1463-72.

19. Gold R. Oral therapies for multiple sclerosis: a review of agents in phase III development or recently approved. CNS Drugs. 2011; 25: 37-52.

20. Fontoura P, Garren H. Multiple sclerosis therapies: molecular mechanisms and future. Results Probl Cell Differ. 2010; 51: 259-85.

21. Linker RA ${ }^{1}$, Lee DH, Ryan S, van Dam AM, Conrad R, Bista P, Zeng W, Hronowsky X, Buko A, Chollate S, Ellrichmann G, Brück W, Dawson K, Goelz S, Wiese S, Scannevin RH, Lukashev M, Gold R. Fumaric acid esters exert neuroprotective effects in neuroinflammation via activation of the Nrf2 antioxidant pathway. Brain 2011; 134:678-92.

22. Gold R, Kappos L, Bar-Or A. "Clinical efficacy of BG-12, an oral therapy, in relapsing-remitting multiple sclerosis:data from the phase 3 DEFINE trial," in proceedings of the 5th Joint Teriannial Congress of European and Americas Committees for Treatment and Research in Multiple Sclerosis (ECTRIMS/ACTRIMS), Amsterdam, The Netherlands, October 2011.

23. Fox RJ, Miller DH, Phillips JT, Hutchinson M, Havrdova E, Kita M, Yang M, Raghupathi K, Novas M, Sweetser MT, Viglietta V, Dawson KT; CONFIRM Study Investigators. "Placebocontrolled phase 3 study of oral BG-12 or glatiramer in multiple sclerosis". N Engl J Med. 2012; 367(12): 1087-97.

24. Gold R, Kappos L, Arnold DL, Bar-Or A, Giovannoni G, Selmaj K, Tornatore C, Sweetser MT, Yang M, Sheikh SI, Dawson KT; DEFINE Study Investigators. "Placebo-controlled phase 3 study of oral BG-12 for relapsing multiple sclerosis," N Engl J Med. 2012; 367(12): 1098-107 